\title{
Teachers' Self-efficacy for Using Information and Communication Technology: The Interaction Effect of Gender and Age
}

\author{
Josip ŠABIĆ ${ }^{*}$, Branislava BARANOVIĆ ${ }^{1}$, Silvia ROGOŠIĆ ${ }^{2}$ \\ ${ }^{1}$ Institute for Social Research in Zagreb, Centre for Educational Research and Development \\ Zagreb, Croatia \\ ${ }^{2}$ Faculty of Teacher Education, University of Zagreb, Zagreb, Croatia \\ e-mail:josip@idi.hr,baranov@idi.hr,silvia.rogosic@ufzg.hr
}

Received: March 2021

\begin{abstract}
The purpose of the study is to examine the moderating effect of age on gender differences in teachers' self-efficacy for using information and communication technology (ICT) in teaching as well as possible variables underlying this effect. Following Bandura's conceptualisation of self-efficacy, we defined teachers' self-efficacy as their confidence in performing specific tasks that require the integration of ICT into the teaching practice. The study was conducted via an online questionnaire on a sample of 6613 elementary and upper secondary school teachers in Croatia. The hierarchical multiple regression analysis was applied. The findings indicate minor gender differences in self-efficacy for using ICT that are more prominent among older teachers and practically non-existent among younger teachers. These effects remain statistically significant after controlling for the type of school where the teacher works, perceived technical and professional support for using ICT in school, and frequency of use of computer programmes in teaching. The interaction effect ceases to be statistically significant after the introduction of length of computer use in teaching and/or attitudes towards computers in the model, indicating that these two variables have a role in low self-efficacy for using ICT among older female teachers. A similar level of self-efficacy for using ICT among young male and female teachers is an encouraging finding which could hopefully be followed by gender equality in other aspects of ICT use. The findings suggest that strategies for enhancing ICT self-efficacy should be particularly targeted at older female teachers. This study contributes to a better understanding of the underresearched topic of gender differences in teacher's ICT self-efficacy.
\end{abstract}

Keywords: age, gender, information and communication technology, self-efficacy, teachers.

\footnotetext{
* Corresponding author:

Institute for Social Research in Zagreb

Centre for Educational Research and Development

Address: Frankopanska 22, 10000 Zagreb, Croatia

Telephone: $+385(0) 14883-551$

Fax: +385 (0)1 4810-263
} 


\section{Introduction}

Today's society witnesses a fast development and implementation of information and communication technology (ICT) in all areas of societal life, including education. Research indicates that teachers play a key role in the successful integration of ICT in schools. In this context, teachers' computer (ICT) self-efficacy and their self-confidence to successfully use ICT in teaching practice are particularly important (Albion et al., 2011; Hong et al., 2014; Krause et al., 2017). Teachers' ICT self-efficacy gained such a prominent role because it has a powerful influence on the teachers' behaviour and achievements. It determines whether the teachers will use ICT, in what way, to what extent and how successful they will be in their use of ICT for instructional purposes. According to Joo et al. (2018:50), teachers' self-efficacy can significantly motivate them to use new technologies in the classroom. Research also indicates that teachers' ICT selfefficacy depends on a number of factors, such as the teachers' age and gender (Scherer and Siddiq, 2015), technology-related attitudes and affect (Cai et al., 2017; Gudek, 2019), teachers' computer experience (Sarfo et al., 2017) and school support (Hatlevik and Hatlevik, 2018).

Gender differences in ICT use and related constructs have received a considerable research attention and have been widely studied in recent years. However, the existing empirical studies show inconsistent and even conflicting results in terms of gender differences in ICT attitudes and behaviours. Meta-analyses (Cai et al., 2017; Whitley, 1997) summarising the findings of individual studies conducted over a period of about 30 years report that this inconsistency in findings blurs the clear understanding of gender differences and makes it difficult to draw reliable conclusions about them. Cai et al. (2017) and Whitley (1997) explain this ambiguity of results as a function of various definitions and operationalisations of the researched constructs and diversity of studied populations. Despite the ambiguity of findings, meta-analyses indicate that gender differences were minimally reduced, especially regarding self-efficacy and affect dimension of attitudes towards ICT use. Males still harbour more favourable attitudes towards ICT use and report a higher level of ICT self-efficacy than females, although the effect sizes of these differences are small (Cai et al., 2017; Whitley, 1997). Such findings emphasise the research and practical need for a continuous exploration of gender differences in ICT use, including the self-efficacy of teachers.

This study is aimed at exploring effects of gender and age on teachers' self-efficacy in using ICT for teaching purposes, while controlling for other variables which influence teachers' ICT self-efficacy - such as technology-related attitudes and affect (Cai et al., 2017), teachers' computer experience (Sarfo et al., 2017) and school support (Hatlevik and Hatlevik, 2018). The examination of gender differences in teachers' ICT self-efficacy is an important research topic for many reasons. According to available statistics, women across the world predominate in teaching, especially in primary education. According to OECD data (OECD.Stat, 2018), female teachers in Finland account for 79.8\% of a total number of teachers in primary education and $67.7 \%$ in secondary education. In United Kingdom, the respective percentages are $86.2 \%$ for primary education and $61.2 \%$ for secondary education, while in Singapore there are $80.7 \%$ female teachers in 
primary education and $63.7 \%$ in secondary education (Ministry of Education of Singapore, 2020). Similarly, female teachers are also prevalent in the Croatian primary and secondary education. Their share in primary education is $86.0 \%$ and $67.1 \%$ in secondary education (Croatian Bureau of Statistics, 2020). Consequently, a successful integration of ICT in education significantly depends on female teachers and their self-efficacy in using ICT for teaching purposes. This feminisation of education emphasises the need to explore female teachers' self-efficacy and gender differences in teachers' ICT selfefficacy.

Researchers also indicate teachers' age as one of key factors influencing their teaching strategies and use of new technologies. Klassen and Chiu (2010), as well as Hoy and Spero (2005), found that teachers 'self-efficacy increases from their early career to mid-career and declines afterwards. In their meta-analysis, Cai et al. (2017) indicate that older female teachers tend to have a lower level of ICT self-efficacy than male teachers. The mentioned studies highlight the importance of researching age and gender-age interaction effect on teachers' ICT self-efficacy. Even more so if we consider the age structure of female teachers, who, as we previously stated, account for the majority of the teacher population. The statistics indicate a relatively considerable share of female teachers over 40 years of age. In Finland, 64\% of primary school teachers are 40 years of age or older; in the United Kingdom, 52\% (OECD.Stat, 2018) and in Singapore 53\% (Ministry of Education of Singapore, 2020). In Croatia, as many as $82 \%$ of primary and secondary school teachers are older than 30 years (Markočić Dekanić et al., 2019).

In summary, the mentioned trends of feminisation of education and the large share of teachers older than 30 and 40 require a deeper insight into teachers' ICT self-efficacy and factors influencing gender and age effects on their ICT self-efficacy. Addressing these issues in the Croatian context, this research aims to contribute to a more comprehensive picture of gender differences in teachers' ICT self-efficacy, which is still an underresearched topic that lacks consistency in research findings. In the Croatian context, the study also has practical importance. It provides empirically grounded insights which are useful for developing policy measures for enhancing ICT self-efficacy of teachers, which is an important prerequisite for the effective integration of ICT into education.

The study is structured as follows: 1) review of relevant studies in the field of gender differences in ICT self-efficacy and the theoretical background of this study; 2) detailed elaboration of research aims and hypotheses; 3) description of research methodology, including a description of the research sample, procedure and instruments; 4) description of the conducted statistical analyses, namely hierarchical multiple regression analysis conducted on the whole sample of teachers and regression analyses performed for males and females separately; analyses providing descriptive statistics; 5) elaboration of main results, which includes presentation of descriptive statistics of the regressors and their relationship with gender and teachers' ICT self-efficacy, as well as description of the results of multiple regression analyses; 6) discussion of the results in the context of the research aims, hypotheses and other studies presented in the research overview; 7) the text ends with the main conclusions drawn from the 
research results, followed by indicating the limitations of research and its implications for further research and practical implications related to improving teachers' ICT selfefficacy in the Croatian context.

\section{Research Overview and Theoretical Background}

As the literature overview shows, many studies exploring teachers' self-efficacy have used Bandura's concept of self-efficacy (Poulou, Reddy and Dudek, 2019; Hatlevik and Hatlevik, 2018; Krause et al., 2017; Scherer and Siddiq, 2015; Klassen and Chiu, 2010). According to Bandura, self-efficacy "refers to a belief in one's capabilities to organise and execute the courses of action required to produce given attainments" (Bandura, 1997, p. 3). Bandura (1997) also indicates that self-efficacy is a domain-specific construct. Self-efficacy researchers in education (Perera, Calkins and Part, 2019; Hatlevik and Hatlevik, 2018; Klassen and Chiu, 2010; Krause et al., 2017; Scherer and Siddiq, 2015; Tarhini et al., 2014), who follow Bandura's self-efficacy conceptualisation, agree that teachers' self-efficacy should reflect their confidence in performing specific tasks in their teaching practice by integrating ICT. It should be noted that, according to Bandura (1997), self-efficacy is a subjective estimation of one's own capabilities which is nonetheless affected by other variables and prior experience of individuals.

Based on Bandura's theory, the concept of self-efficacy is often used in studies exploring gender differences in teachers' use of ICT for teaching purposes, providing a theoretical basis for conceptualising ICT teachers' self-efficacy in empirical studies, including this study. Scherer and Siddiq (2015) conducted a study on teachers' computer self-efficacy using the data obtained from the Norwegian secondary school teachers who participated in the 2013 International Computer and Information Literacy Study. Teachers' computer self-efficacy was conceptualised as their confidence in performing basic and advanced skills in using computers and the use of computers for instructional purposes (Scherer and Siddiq, 2015, p. 48). The results revealed that male teachers, compared to female teachers, showed higher levels of computer selfefficacy in basic and advanced operational skills. However, there was no statistically significant gender difference in the third dimension of computer self-efficacy - using computers for instructional purposes. As the authors noted, the use of computers for teaching purposes may include aspects of pedagogical competence which makes this construct different from the constructs related to the competence of operational use of computers. This finding points to the relevance of exploring differences in teaching practices and pedagogical knowledge and their effects on gender differences in ICT self-efficacy.

In Siddiq and Scherer's (2016) research on the relationship between the teachers' emphasis on the development of students' ICT skills and computer self-efficacy, gender and age were investigated as moderators. The findings show that, contrary to age, the moderation effect of gender was limited, relating only to the use of computers for instructional purposes. The interaction between gender and age did not show a statistically significant moderation effect. The research points to the important role of age in 
teachers' self-efficacy, particularly in older teachers. According to the authors, further research should be carried out to obtain a more comprehensive and clearer picture of moderation effects of age and gender on the relation between ICT-related constructs.

The effect of age on gender differences in ICT self-efficacy of teachers was rarely a subject of studies. Studies often perceive age differences as a generational issue where older teachers are less exposed to the ICT experience, have lower ICT selfefficacy and generally a less favourable attitude towards ICT use (Guo et al., 2008; Prensky, 2001; Salajan et al., 2010). Sarfo et al. (2017) investigated gender differences in teachers' computer self-efficacy in relation to their age and computer experience on a sample of senior high school teachers in Ghana. The data show that there was no gender difference in the overall computer self-efficacy. However, when selfefficacy was itemised into specific skills, it appeared that male teachers had a higher level of self-efficacy in web-based skills compared to female teachers, while gender differences were not found in basic computer skills and media-related skills. Such findings suggest that gender differences in ICT self-efficacy are associated with the use of different computer programmes whereby men are more likely to use advanced and more complex computer programmes than women. Regarding the effect of age, the findings also point out that its effect on ICT self-efficacy varies according to the type of computer applications. More precisely, there was no statistically significant effect of age for basic and web-based applications, only for media-related skills in favour of the younger teachers aged 20-30 years. Interestingly, the interaction effect of age and gender on ICT self-efficacy was not identified, which supports the previously mentioned findings by Siddiq and Scherer (2016).

Some researchers associate the impact of age on ICT self-efficacy with emotional attitude towards ICT use, pointing to a positive relation between age and computer anxiety (Chaffin and Harlow, 2005; Czaja et al., 2006; Turner et al., 2007). Concerning the studies on the relationship of ICT self-efficacy and computer anxiety of teachers, the studies provide different findings. Sarfo et al. (2017, p. 21), referring to the research findings by Compeau and Higgins (1995), state that the teachers with a lower level of self-efficacy are more anxious about working with computers than the teachers with a higher level of computer self-efficacy. The relationship between anxiety and ICT self-efficacy was also explored from the gender perspective. Papanastasiou and Angeli (2008) found that male Greek Cypriot teachers had a higher level of computer anxiety than their female colleagues. Contrary to this, in their meta-analyses of 50 papers on gender differences in attitudes towards ICT use published from 1997 to 2017, Cai et al. (2017) report a tendency of women to show greater anxiety than men. However, they point out that, despite maintaining this tendency, the gender gap is narrowing. From the point of view of the present research, these studies are instructive because they conceptualise anxiety as a component of computer attitude or, more precisely, as an emotional component of computer attitudes, what was also covered in this study.

Based on Bandura's $(1994,1997)$ statement on the sources of self-efficacy, the relationship between the teachers' computer experience and contextual factors and their ICT self-efficacy has also been explored (Hatlevik and Hatlevik, 2018; Papanastasiou and Angely, 2008; Sarfo et al., 2017). Sarfo et al. (2017, p. 25) found that there was an 
interaction effect between male and female teachers with a low level of computer experience and male and female teachers with a high level of computer experience on their computer self-efficacy slightly in favour of male teachers with a high level of computer experience. Hatlevik and Hatlevik (2018) confirmed a positive relationship between teachers' ICT self-efficacy and their ICT use in the teaching practice. Said authors, like Papanastasiou and Angeli (2008), also found a positive relationship between teachers' ICT self-efficacy and their work context, i.e., collegial and school management support. This points to the relevance of school's support in exploring teachers' ICT self-efficacy with respect to their age and gender differences.

In summary, the review of the studies shows that a considerable attention has been attributed to the research on teachers' ICT issues in general, but not to gender differences in ICT self-efficacy, especially with respect to age, as noted by Siddiq and Scherer (2016) and Sarfo et al. (2017). The cited studies confirm that individual effects of age and gender, as well as their interaction effect on gender differences in teachers' selfefficacy, exist in different educational contexts and societies. The scarcity of empirical studies and differences in their findings point to the need for a further examination of the role of gender and age in teachers' ICT self-efficacy and variables that influence their effects on gender differences in different educational and societal contexts. This study will contribute to the field by providing empirical insights into the role of gender and age in teachers' self-efficacy in using ICT for instructional purposes in primary and secondary education in the Croatian context.

\section{Aims and Hypotheses}

The Croatian educational system consists of compulsory elementary schools (primary and lower secondary schools), upper secondary education (gymnasiums and vocational schools) and tertiary education (polytechnics and universities). After finishing compulsory elementary school at the age of 14 or 15 , the students in Croatia enrol into upper secondary schools. They can choose between academically oriented gymnasiums that prepare students for higher education and vocational schools that are more oriented on preparing the students for the labour market. This research focusses on the elementary and upper secondary education.

The digitalisation of elementary and secondary schools in Croatia was intensified by the Government Strategy of Education, Science and Technology (Government of the Republic of Croatia, Expert Committee, 2014) and the national project e-Schools within which this research was conducted. The process of school digitalisation raised the questions of teachers' preparedness to integrate ICT into their teaching practice, including ICT gender differences. Gender differences are even more important since in the school year 2018/2019 the share of female teachers in Croatia was $86 \%$ in elementary schools and $67.1 \%$ in secondary schools (Croatian Bureau of Statistics, 2020). Additionally, the age composition of the teacher population, which includes all subject teachers in elementary and upper secondary schools, indicates that over the last 5 years the number of teachers under the age of 30 has decreased by $5 \%$, while the number of 
teachers aged 30 to 50 has decreased by $11 \%$. As a result, the current teacher population has only $8 \%$ of teachers under the age of $30,67 \%$ of teachers between the ages of 30 and 49 , and $24 \%$ of teachers over the age of 50 (Markočić Dekanić et al., 2019). The stated gender composition and changes in the age structure of the teacher population raise the questions of how the teachers ' gender and age affect the integration of ICT into their teaching practice and of the extent of teachers` ICT self-efficacy. The review of the literature indicated that in this context, gender differences in ICT self-efficacy are one of the vital but unexplored problems. This is especially true for Croatia, where, to the best of the knowledge of the authors of this study, gender differences in teachers' ICT self-efficacy have not been the subject of research so far but have been marginally addressed in only a few studies.

This study has three aims:

1) To examine the possible moderating effect of age on gender differences in teachers'self-efficacy for using ICT in teaching

Following the example of other studies that have used Bandura's conceptualisation of self-efficacy (Hatlevik and Hatlevik, 2018; Sarfo et al., 2017), we understand teachers' self-efficacy as their confidence in performing specific tasks that require the integration of ICT into the teaching practice. Consistently with the findings from the earlier studies that men are more self-efficient for using ICT than women (Cai et al., 2017; Whitley, 1997), we expect that male teachers will report higher levels of self-efficacy in comparison with their female counterparts (H1). We further expect higher levels of self-efficacy for using ICT among younger teachers, who had better opportunities to embrace digital tools at an earlier age, than among older teachers $(\mathrm{H} 2)$. Finally, we expect the gender-age interaction effect (i.e., the moderating effect) on teachers' self-efficacy for using ICT (H3). More specifically, we anticipate smaller gender differences in selfefficacy among younger teachers who were obliged to take mandatory courses in ICT during their upper secondary education and/or to use ICT in their studies regardless of their gender.

2) To identify other variables that explain gender-age interaction effect on teachers' self-efficacy in using ICT in teaching

Furthermore, the aim of this study is to inspect the possible reasons for the aforementioned interaction effect and a relatively low level of self-efficacy for using ICT among older female teachers. In doing so, we will control for the effects of the following variables: the type of school where the teachers work (elementary vs. upper secondary school: i.e., gymnasium or vocational school), teachers' perceived level of technical and professional support in their school, frequency of the teachers' use of simple and complex computer programmes, length of computer use in teaching, and teachers' attitudes towards computers.

In general, we expect that upper secondary school teachers will be more selfefficient regarding the use of ICT than their elementary school counterparts, as a result of a more complex usage of technology in teaching older cohorts of students (H4). Furthermore, we expect higher levels of self-efficacy among the 
teachers who experience higher levels of technical and professional support in their schools (H5) (Hatlevik and Hatlevik, 2018), who use computer programmes in teaching more frequently (H6) (Hatlevik and Hatlevik, 2018), who have been using a computer in teaching for a longer period of time (H7) (Sarfo et al., 2017), as well as among the teachers who have more positive attitudes towards computers (H8) (Cai et al., 2017).

By adding these variables successively into the statistical model, we aim to determine how they affect the main effects of gender and age on self-efficacy for using ICT in teaching, as well as the gender-age interaction effect.

3) To identify the strongest regressor of teachers' self-efficacy in using ICT in teaching

In addition, we aim to explore the effect sizes of individual regressors of teachers' self-efficacy for using ICT to find the strongest regressor. Although this aim is exploratory, we expect that at least some of the regressors will yield stronger effects in comparison with both gender and age (H9). This expectation is in line with the previous findings that gender differences in ICT self-efficacy show small effect sizes (Cai et al., 2017; Whitley, 1997), while statistical significance of age effects on ICT self-efficacy depends on how ICT is operationalised (Sarfo et al., 2017). Therefore, other variables could probably provide a better explanation of variations between teachers in ICT self-efficacy. For example, Gudek (2019) found a substantial relationship between computer self-efficacy of teacher candidates and their attitudes towards digital technology, while Krause et al. (2017) concluded that teachers' attitudes towards using ICT are one of the essential predictors of successful integration of ICT into teaching.

\section{Methodology}

\subsection{Sample and Procedure}

This study was based on a broader research project "The use of ICT in learning, teaching and assessment in Croatian elementary and secondary schools" that was conducted by the Croatian Academic and Research Network - CARNET and the Institute for Social Research in Zagreb. The data for this study were collected in September 2018 using the online questionnaire that was distributed to the principals of all elementary and upper secondary schools in Croatia. The school principals were asked to forward the questionnaire link to all teachers employed in their respective schools. The questionnaire was created using the LimeSurvey platform (LimeSurvey $\mathrm{GmbH}$, 2018). It consisted of multiple-choice and Likert-type items. The participants were not able to skip items and they had to answer each item in order to move onto the next item. The completion of the questionnaire was anonymous and voluntary. About $13 \%$ of all elementary school teachers $(\mathrm{N}=4395 ; 85.2 \%$ females) and $8 \%$ of all upper secondary school teachers $(\mathrm{N}=2218 ; 69.6 \%$ females $)$ in Croatia completed the ques- 
tionnaire (total $\mathrm{N}=6613 ; 80 \%$ females). Among the elementary school teachers from the sample, the dominant age categories were $31-40$ years $(36.1 \%)$ and $41-50$ years (30.7\%). Upper secondary school teachers were dominantly $31-40$ years old $(30.7 \%)$ or $41-50$ years old $(27.1 \%)$. The distribution of teachers in the sample with respect to gender and type of school differed negligibly from the distribution in the population $\left(\chi^{2}=467.10 ; \mathrm{p}<.01 ;\right.$ Cramér's $\left.\mathrm{V}=.084\right)$.

\subsection{Instruments}

Among others, the questionnaire contained different constructs that were in line with the aims and hypotheses of this research. We used the scale of teachers' self-efficacy for using ICT in teaching and the scale of computer attitudes, both devised by Papanastasiou and Angeli (2008). Rogošić (2015) translated these scales and used them in her research on the ICT use among the Croatian elementary school teachers in Zagreb (the capital of Croatia). Furthermore, the frequency of use of computer programmes was measured using the list of computer programmes by Papanastasiou and Angeli (2008) that was expanded for the purpose of this study. The questionnaire also contained the original scale of perceived technical and professional support for using ICT in school, items on demographics, as well as one item about the length of computer use in teaching.

Teachers'self-efficacy for using ICT in teaching. This construct is operationalised as the teachers' self-confidence in using computer programmes/applications of different complexity in their work and in teaching the students to apply ICT in their learning. The scale consisted of seven Likert-type items (e.g., "I feel confident that I can use email to communicate with my students"; "I can teach my students how to make their own web pages") on a five-point continuum ranging from "completely disagree" to "completely agree" $(\alpha=.88)$. The average result on all seven items was used as an outcome in the analyses. The principal axis factoring supported the unidimensionality of the scale.

Computer attitudes. This construct was operationalised as the teachers' cognitive, affective and behavioural evaluation of computers in the context of teaching and learning. The scale consisted of six Likert-type items (e.g., "The computer helps students understand concepts in a more effective way"; "The use of computers in teaching and learning stresses me out"; "If something goes wrong, I will not know how to fix it") on a five-point continuum ranging from "completely disagree" to "completely agree" $(\alpha=.91)$. The average result on all six items was used as a regressor. The scale was recoded so that higher scores imply more positive attitudes towards computers. The principal axis factoring supported the unidimensionality of the scale.

Frequency of use of computer programmes. Teachers were asked to estimate how often they used different computer programmes in teaching on a five-point continuum from "never" to "every day". The list contained 11 computer programmes. Two factors were extracted: the frequency of use of simple computer programmes (text editors, presen- 
tation programmes, websites/web portals, specialised educational websites; $\alpha=.65$ ) and the frequency of use of complex computer programmes (multimedia tools, webpage editors, concept map tools, database software, publishing software, modelling software, computer simulation software; $\alpha=.82$ ). The average results on two sets of items were used as regressors.

Perceived technical and professional support for using ICT in school. This construct is operationalised as the teachers' perceived level of school's ICT equipment adequacy, of its availability to both the teachers and their students, as well as the teachers' opportunity to seek help regarding ICT use. A new scale was constructed for this research project that consisted of seven Likert-type items ("I have internet access at school", "Internet access is available to my students at school", "At school, I have the necessary ICT equipment for teaching", "At school, my students have the necessary ICT equipment for classes in my subject", "At school, I get the necessary professional help and support for ICT use in teaching", "At school, I have the support of other teachers to use ICT in teaching", "The school enables the necessary professional development for the application of ICT in teaching") on a five-point continuum ranging from "completely disagree" to "completely agree" $(\alpha=.86)$. A pilot study was conducted on a small sample of elementary and upper secondary school teachers to check the comprehensibility of the items. The average result on all seven items was used as a regressor. The principal axis factoring supported the unidimensionality of the scale.

Items on demographics. Teachers were asked to specify their gender (female or male), age (30 or less, 31-40, 41-50, 51-60, 61 or more) and the type of school where they work (elementary school or upper secondary school; if they chose upper secondary school, they were asked to further specify whether it was a gymnasium or a vocational school). Gender and type of school were used as categorical regressors and age was treated as interval regressor in the analysis.

Length of computer use in teaching (in years). Teachers were asked to indicate how many years they had been using computer in teaching. Possible answers were: 5 years or less, 6-10 years, 11-20 years, 21-30 years, and 31 years or more. This variable was used as an interval regressor in the analyses.

\subsection{Statistical Analysis}

The hierarchical multiple regression analysis was conducted in order to address the study aims. Teachers' self-efficacy in integrating ICT into teaching was used as the outcome variable. The following variables were introduced as regressors in the successive steps of the model - the first step: teachers' gender, age, and gender-age interaction; the second step: type of school (elementary, gymnasium or vocational school) and perceived technical and professional support for using ICT in school; the third step: frequency of use of simple and complex computer programmes; the fourth step: length of computer use in teaching and computer attitudes. The first step of the model related to the first study aim and tested the main effects of gender and age as well as 
gender-age interaction effect, i.e., the moderating effect of age on gender differences in teachers' self-efficacy for using ICT. Steps 2 to 4 related to the second study aim - to identify the possible reasons of gender-age interaction effect on teachers' self-efficacy for using ICT. In other words, we wanted to check if the interaction effect remains statistically significant after the introduction of different regressors. Furthermore, steps 2 to 4 related to the third aim as well - to identify the strongest regressor of teachers' self-efficacy for using ICT.

In addition, hierarchical multiple regression models were tested for females and males separately in order to check if the regressor variables (age, type of school, perceived technical and professional support for using ICT, frequency of use of computer programmes, length of computer use and computer attitudes) display similar effects across genders.

Since the number of uncompleted questionnaires was negligible, we conducted a complete case analysis. All variance inflation factor values (VIF) were smaller than two, meaning that there were no signs of multicollinearity.

\section{Results}

\subsection{Descriptive Statistics}

Descriptive statistics of the regressors and the outcome are presented in Table 1. A large majority of participants in this sample are females. Almost two thirds of teachers are in their thirties or forties. About two thirds of teachers work in elementary schools, while the rest of them work in upper secondary schools (gymnasium and vocational schools). On average, teachers experience high levels of technical and professional support for using ICT in their schools. Likewise, they report a frequent use of simple computer programmes. On the other hand, teachers on average rarely use complex computer programmes. More than $75 \%$ of teachers have been using computer in teaching for 10 years or less. On average, they have positive attitudes towards computers and high levels of self-efficacy for using ICT in teaching.

There are more female teachers in elementary schools, while males are more prevalent in upper secondary vocational schools. On average, males give higher estimates of technical and professional support for using ICT than females. Furthermore, they more frequently use complex computer programmes and use computer in teaching for a somewhat longer time than females. Gender difference in the frequency of using simple computer programmes is negligible. Males have more positive attitudes towards computers and higher self-efficacy for using ICT than females. However, it should be noted that the aforementioned gender differences are small and that both males and females have relatively high levels of self-efficacy for using ICT.

On a bivariate level, all regressors are associated with the outcome in the expected direction. 
Table 1

Descriptive statistics of the variables and their relationship with gender and teachers' self-efficacy for using information and communication technology

\begin{tabular}{|c|c|c|c|c|c|c|c|}
\hline Variables & $\mathrm{M}(\mathrm{SD}) / \%$ & $\begin{array}{l}\mathrm{M}(\mathrm{SD}) \\
/ \% \\
\text { (males) }\end{array}$ & $\begin{array}{l}M(\mathrm{SD}) \\
/ \% \\
\text { (females) }\end{array}$ & $\begin{array}{l}\mathscr{E} \\
\tilde{\Xi}\end{array}$ & $\alpha$ & $\begin{array}{l}\text { Relationship } \\
\text { with gender }\end{array}$ & $\begin{array}{l}\text { Relation- } \\
\text { ship with } \\
\text { self-efficacy }\end{array}$ \\
\hline \multicolumn{8}{|l|}{ Regressors } \\
\hline Gender & & & & & & & $.12^{* *}$ \\
\hline Female (0) & $80.0 \%$ & & & & & & \\
\hline Male (1) & $20.0 \%$ & & & & & & \\
\hline Age & & & & & & -.00 & $.16^{* *}$ \\
\hline$<30$ & $11.0 \%$ & $11.2 \%$ & $11.0 \%$ & & & & \\
\hline $31-40$ & $34.3 \%$ & $38.2 \%$ & $33.3 \%$ & & & & \\
\hline $41-50$ & $29.5 \%$ & $23.5 \%$ & $31.0 \%$ & & & & \\
\hline $51-60$ & $21.6 \%$ & $21.8 \%$ & $21.5 \%$ & & & & \\
\hline$>61$ & $3.6 \%$ & $5.3 \%$ & $3.2 \%$ & & & & \\
\hline Type of school & & & & & & $\chi^{2}=259.8^{* *}$ & $\mathrm{~F}=26.9^{* *}$ \\
\hline Elementary school (1) & $66.5 \%$ & $49.1 \%$ & $70.8 \%$ & & & Cramer's V $=.20$ & $1<2,3$ \\
\hline Gymnasium (2) & $10.8 \%$ & $12.4 \%$ & $10.3 \%$ & & & & \\
\hline Vocational school (3) & $22.8 \%$ & $38.5 \%$ & $18.8 \%$ & & & & \\
\hline $\begin{array}{l}\text { Technical and professional } \\
\text { support }\end{array}$ & $3.6(0.92)$ & $3.8(0.87)$ & $3.5(0.93)$ & $1-5$ & .86 & $.13^{* *}$ & $.33^{* *}$ \\
\hline $\begin{array}{l}\text { Simple computer progra- } \\
\text { mmes - frequency of use }\end{array}$ & $3.6(0.96)$ & $3.6(0.95)$ & $3.6(0.96)$ & $1-5$ & .78 & $.03^{*}$ & $.34^{* *}$ \\
\hline $\begin{array}{l}\text { Complex computer progra- } \\
\text { mmes - frequency of use }\end{array}$ & $1.3(0.48)$ & $1.4(0.63)$ & $1.2(0.43)$ & $1-5$ & .86 & $.14^{* *}$ & $.38^{* *}$ \\
\hline $\begin{array}{l}\text { Use of computer in teach- } \\
\text { ing (years) }\end{array}$ & & & & & & $.06^{* *}$ & $.28^{* *}$ \\
\hline 0 & $9.6 \%$ & $11.9 \%$ & $9.0 \%$ & & & & \\
\hline Less than 5 & $31.9 \%$ & $26.6 \%$ & $33.3 \%$ & & & & \\
\hline $6-10$ & $35.1 \%$ & $29.9 \%$ & $36.4 \%$ & & & & \\
\hline $11-20$ & $20.8 \%$ & $26.5 \%$ & $19.4 \%$ & & & & \\
\hline $21-30$ & $2.3 \%$ & $4.4 \%$ & $1.8 \%$ & & & & \\
\hline 31 or more & $0.3 \%$ & $0.8 \%$ & $0.1 \%$ & & & & \\
\hline Computer attitudes & $3.3(0.81)$ & $3.4(0.78)$ & $3.3(0.81)$ & $1-5$ & .91 & $.07^{* *}$ & $.48^{* *}$ \\
\hline \multicolumn{8}{|l|}{ Outcome } \\
\hline $\begin{array}{l}\text { Teachers' self-efficacy for } \\
\text { using ICT }\end{array}$ & $3.62(0.871)$ & $3.8(0.89)$ & $3.6(0.86)$ & $1-5$ & .88 & $.12^{* *}$ & \\
\hline
\end{tabular}

Note: ${ }^{* *} \mathrm{p}<.01,{ }^{*} \mathrm{p}<.05 ;{ }^{\text {a }}$ females $=0$, males $=1$

\subsection{Hierarchical Multiple Regression Analysis}

In accordance with the hypotheses related to the first aim, the hierarchical multiple regression analysis shows that males and younger teachers report higher levels of self-efficacy for using ICT in teaching in comparison with females and older teachers, respectively (Table 2, column "Whole sample"; H1 and H2 confirmed). The effects of gender and age 
are small but statistically significant in all steps of the model, i.e., after the introduction of all regressor variables. As expected, gender differences in self-efficacy for using ICT are greater among older teachers and practically non-existent among the youngest ones (Table 2; Fig. 1; H3 confirmed).

In the context of the second aim, it can be noted that gender-age moderation effect on teachers' self-efficacy for the ICT use holds for both elementary and upper secondary school teachers (Fig. 1). The gender-age interaction effect is relatively robust (Table 2, column "Whole sample"), in a way that it remains statistically significant even after the introduction of the type of school and the estimates of technical and professional support in the regression model (step 2), as well as after the introduction of the frequency of use of simple and complex computer programmes (step 3). The interaction effect ceases to be statistically significant after the introduction of the length of computer use in teaching (in years) and the computer attitudes in the model (step 4). A more detailed analysis with the separate introduction of these two variables in the model (not reported here) shows that both the length of computer use and the computer attitudes cancel the effect of gender-age interaction. Apparently, older female teachers on average have more negative attitudes towards computers in comparison to other teachers. Moreover, they use computers in teaching for a shorter period of time than other teachers, which also affects their self-efficacy for using ICT.

It should be noted that even older female teachers report average levels of self-efficacy for using ICT (value 3 - "I neither agree nor disagree"; Fig. 1). In other words, their scores are low only relatively but not absolutely. In addition, teachers who work in upper secondary vocational schools have a higher level of self-efficacy for using ICT than their colleagues from elementary schools (H4 partially confirmed). However, no difference in self-efficacy was found between gymnasium teachers and elementary school teachers. Teachers provided higher estimates of self-efficacy for using ICT if they received higher levels of technical and professional support in their schools (H5 confirmed), if they use computer programmes more often (H6 confirmed), if they use computers in teaching for a longer time (H7 confirmed) and if they have more positive attitudes towards computers (H8 confirmed).

Concerning the third aim, positive computer attitudes were the single strongest regressor of the teachers' self-efficacy for using ICT, which is consistent with the results of bivariate analyses (Table 1). Furthermore, the model with only gender, age and genderage interaction (Table 2, column "Whole sample", step 1) explains only $4.3 \%$ of variance in self-efficacy for using ICT. In comparison, the full model (step 4) explains nearly $40 \%$ of variance of the outcome, which suggest that other variables are more important than gender and age for explaining self-efficacy for using ICT (H9 confirmed).

Additional hierarchical regression models (Table 2, columns "Females" and "Males") show that individual regressors have similar effects on self-efficacy for using ICT for teachers of both genders, i.e., both directions and values of regression coefficients are rather similar for females and males. The only exception from this pattern is the absence of age effect in male teachers' data in step 1, which indicates a greater importance of age for self-efficacy for using ICT among females. In step 4, both models explain a similar percentage of variance $(40.4 \%$ and $32.6 \%$ for females and males, respectively). 


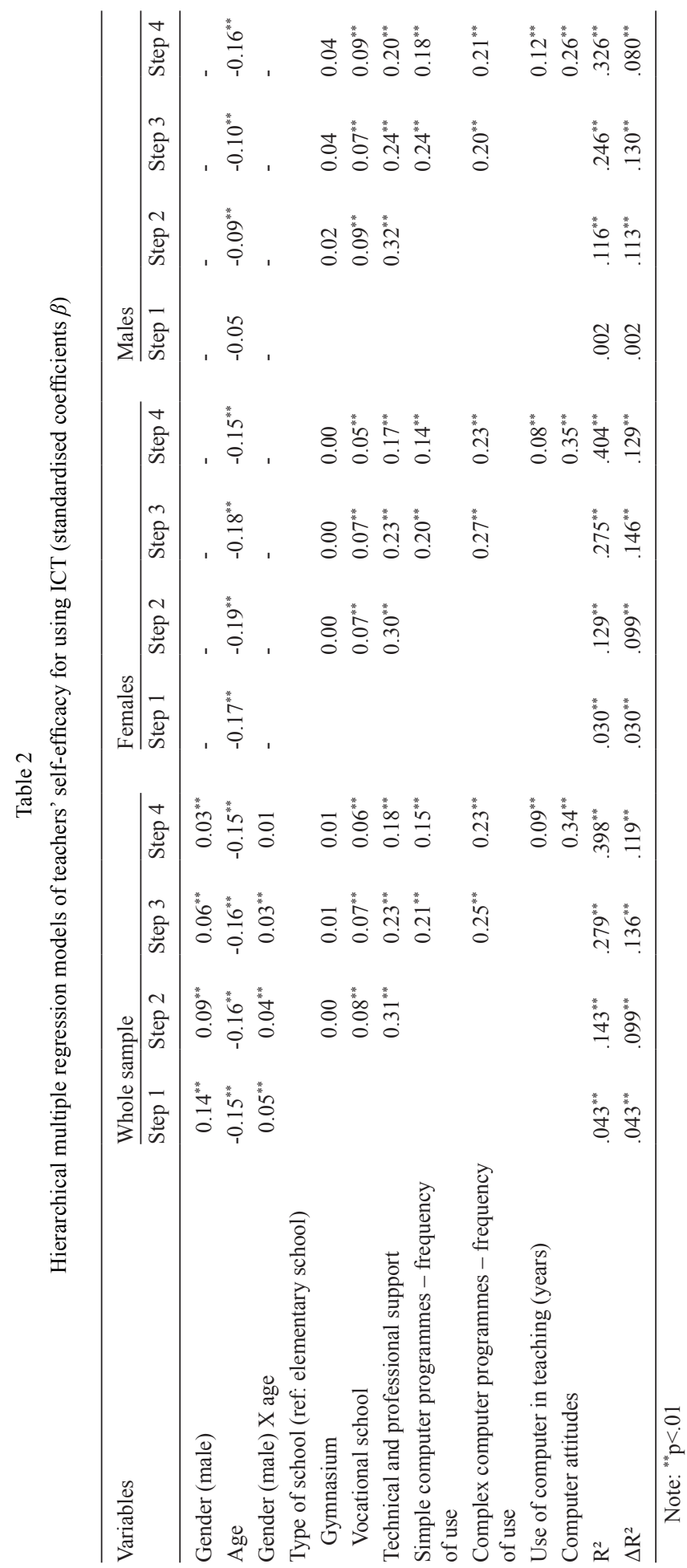




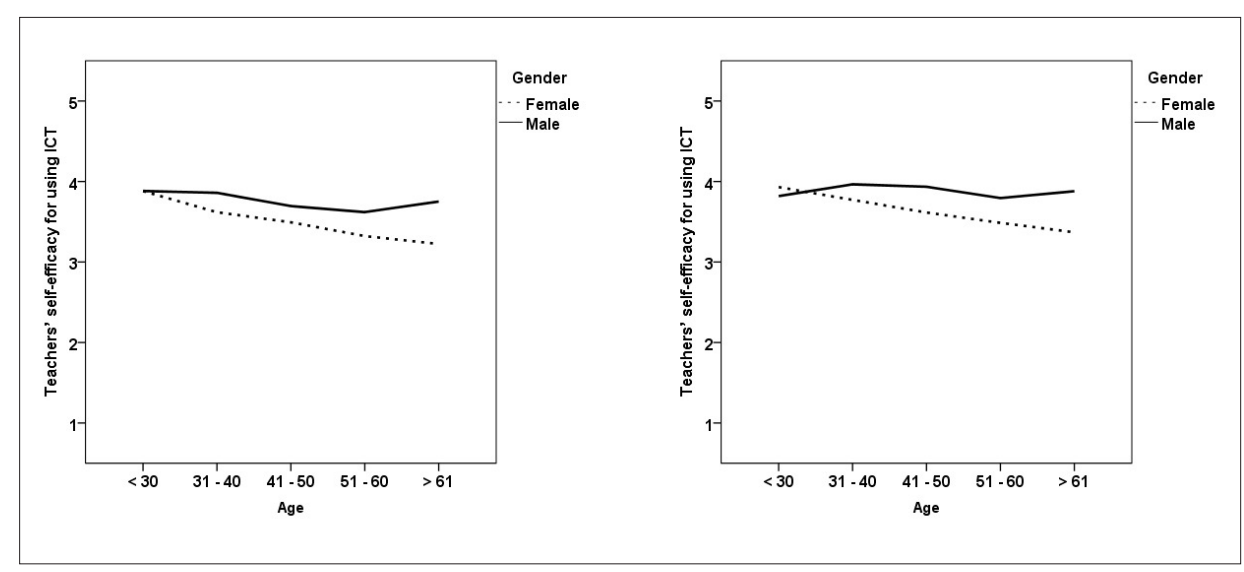

Fig. 1. Moderation effect of age on gender differences in teachers' self-efficacy for using ICT (left - elementary school, right - upper secondary school).

\section{Discussion}

As we have already mentioned, this study has three aims: the first aim is to examine the moderating effect of age on gender differences in teachers' self-efficacy for using ICT in teaching, the second aim is to identify variables that explain gender-age interaction effect on teachers' self-efficacy in using ICT in their teaching, while the third aim is to identify the strongest regressor of teachers' self-efficacy in using ICT in their teaching.

The findings relating to the first aim reveal that the effects of gender and age on teachers ` ICT self-efficacy are statistically significant but minor. As hypothesised, they indicate minor differences in self-efficacy for using ICT between male and female teachers in favour of male teachers ( $\mathrm{H} 1$ confirmed). This finding is consistent with the results of meta-analyses of individual empirical studies conducted over the last several decades (Cai et al., 2017; Whitley, 1997). According to them, despite the reduction of gender differences, men still have higher ICT self-efficacy than women. The research confirms that this is true for gender differences in the Croatian educational context where male teachers still have greater self-efficacy than female teachers, although this difference is small.

The effect of age indicates that younger teachers are more self-efficient in using ICT than the older ones (H2 confirmed). It should also be indicated that gender differences in teachers' self-efficacy for using ICT in teaching are smaller among younger teachers than among older teachers, indicating the relevant role of age in gender differences in teachers' ICT self-efficacy (H3 confirmed). More precisely, gender differences are practically non-existent among the youngest teachers (Fig. 1). Similarly, studies carried out by Sarfo et al. (2017) and Siddiq and Scherer (2016) also found effects of gender and age on teachers' computer or ICT self-efficacy. Their research indicates that the effects of 
gender and age on teachers' ICT self-efficacy vary depending on the teachers ' computer operational skills (Siddiq and Scherer, 2016) and the type of computer programme they use (Sarfo et al. 2017). This is suggestive for further research on gender differences in teachers' ICT self-efficacy in the Croatian context, pointing to the need for a more thorough research into the relationship between ICT self-efficacy and constructs such as the complexity of computer programmes and the diversity of teachers' computer skill for ICT integration into teaching.

Concerning the second study aim, which is focused on the explanation of genderage interaction effect on teachers' self-efficacy in using ICT, the following findings are relevant. First and foremost, the finding that all regressor variables used for explaining the gender-age interaction effect are associated with teachers' ICT self-efficacy in the expected direction on the bivariate level and in the regression analysis (Table 1 and Table 2; H4 partially confirmed; H5, H6, H7 and H8 confirmed). The only exception is that the teachers from gymnasiums did not differ from elementary school teachers in the average levels of self-efficacy for using ICT, as we anticipated. The hypothesis was that the upper secondary school teachers, i.e., vocational school teachers and gymnasium teachers would have a higher level of ICT self-efficacy than their elementary school counterparts, as a result of a more complex use of ICT in teaching older cohorts of students. The reason why vocational school teachers, unlike gymnasium teachers, have a higher level of ICT self-efficacy and differ from elementary school teachers could be found in their technologically-oriented professional profile and vocational school curricula that require the application of more complex ICT programmes. In contrast to this study focused on teachers' ICT self-efficacy, the studies on the association of teachers' self-efficacy for classroom management and student engagement with grade levels found that teachers in higher grade levels had lower self-efficacy compared to teachers in lower grade levels (Klassen and Chiu, 2010; Wolters and Daugherty, 2007). This difference suggests that the relationship between grade levels and teachers' self-efficacy varies depending, among other factors, on the type of teachers' self-efficacy.

Regarding the gender-age interaction effect on teachers ' ICT self-efficacy, the findings of this study show that it is relatively robust. They indicate that the gender-age interaction effect ceased to be statistically significant only in the last step of the regression analysis, after the introduction of the length of computer use in teaching and the computer attitudes into the model. This suggests that these two variables play a role in the low level of ICT self-efficacy among older teachers, in particular among older female teachers. The importance of the role of age in ICT self-efficacy of female teachers was confirmed by the findings of separate hierarchical regression analyses conducted on a subsample of male and female teachers indicating the absence of age effect in male teachers' data in step 1 (Table 2). In this context, it should be noted that older female teachers used computer in teaching for a shorter period of time than their male counterparts and that they tend to have a more negative attitude towards computer than the older male teachers.

By reviewing these findings in the context of other studies, it should be noted that the finding on the effect of gender-age interaction on teachers' ICT self-efficacy dif- 
fers from the findings by Sarfo et al. (2017) and Siddiq and Scherer (2016). They did not identify the effect of gender-age interaction on teachers' self-efficacy in the use of ICT, hence their studies do not support the findings of this study. This inconsistency in the findings may stem from the differences in the operationalisation of major concepts (e.g., self-efficacy in using different computer programmes) and differences in research samples (primary school teachers, lower secondary school teachers and senior high school teachers). As the literature overview indicates, the gender-age interaction effect on the gender differences in teachers' ICT self-efficacy is an underresearched and undertheorised research problem. In the context of scarce research, the mentioned variability and inconsistency in the findings confirms the need for further research of the moderating effect of age on gender differences in teachers' self-efficacy for using ICT in teaching.

However, the findings of this study regarding the significant effects of previous experience with the use of ICT on gender differences in teachers' ICT self-efficacy are consistent with the findings of other studies. For example, Hatlevik and Hatlevik (2018) as well as Papanastasiou and Angeli (2008) also found a positive relationship between teachers' self-efficacy and the length of ICT use in their teaching practice, while Sarfo et al. (2017) identified the interaction effect of gender and computer experience of teachers on their computer self-efficacy in favour of males with a higher level of computer experience.

As previously mentioned, in this study, computer attitudes are an important variable for explaining the gender-age effect on teachers' ICT self-efficacy, especially in terms of older female teachers who tend to have more negative attitudes towards computers compared to the older male teachers. Related to the third aim, it shows that computer attitudes, as the single strongest regressor of ICT self-efficacy (H9 confirmed), explain gender differences in self-efficacy for using ICT in teaching more than the other variables (type of school, technical and professional support in school, frequency of use of simple and complex computer programmes and number of years of computer use in teaching). This is not surprising if we consider that the teachers' attitudes are one of the essential prerequisites for the successful integration of ICT into teaching and into the classroom in general (Krause et al., 2017).

Some studies suggest that more negative attitudes of female teachers towards computers could be accounted for by their higher level of computer anxiety, which is negatively associated with computer self-efficacy (Cai et al., 2017; Sarfo et al., 2017; Whitley, 1997). This points to the relevance of a more detailed research into the role of computer anxiety as a separate construct in gender differences in teachers ' ICT selfefficacy in the future.

Finally, the variance of teachers' ICT self-efficacy shows that computer attitudes and other variables (type of school, technical and professional support in school, frequency of use of simple and complex computer programmes and number of years of computer use in teaching) are more important than gender and age in explaining the differences in ICT self-efficacy, confirming thus the small effects of age and gender on teachers' ICT self-efficacy. 


\section{Conclusions, Limitations and Implications of the Research}

Overall, these findings show that gender differences in teachers' ICT self-efficacy exist, but they are minor. As a result, two findings are particularly important: 1) males and younger teachers report higher levels of self-efficacy for using ICT in teaching than females and older teachers, respectively; 2) gender differences in self-efficacy are greater among older teachers, while they are practically non-existent among the youngest ones. This moderation effect reveals an important role of age in gender differences in ICT self-efficacy addressing lower self-efficacy of older female teachers compared to other teachers. In this regard, it is important to emphasise that both male and female teachers have a relatively high level of self-efficacy in the use of ICT in their teaching.

The findings also suggest that ICT attitudes and previous experience of teachers in the use of ICT play an important role in their ICT self-efficacy, especially among older female teachers who have more negative ICT attitudes and who have been using ICT in teaching for a shorter period of time than their male colleagues.

As noted by other researchers (Siddiq and Scherer, 2016; Sarfo et al., 2017), gender differences in teachers' ICT self-efficacy have previously been researched but very rarely, especially in terms of the role of age in ICT self-efficacy. Scarcity and inconsistencies in research findings call for further research into gender differences in teachers' ICT self- efficacy in different societal contexts and educational settings. Even more so as this is an important topic in many countries, which has been shown in the overview of previous research. This research contributes to the existing studies by highlighting the role of age of primary and secondary school teachers in Croatia in gender differences in ICT self-efficacy. In this respect, the finding which points to the greater importance of age for ICT self-efficacy among females as compared to males is quite significant.

However, the study has some limitations. This research design was transversal, which allowed us to identify gender differences in teachers' ICT self-efficacy. A longitudinal study is required to test whether these differences increase with age within the same sample of teachers.

Furthermore, taking into account the impact of school subjects taught by teachers would contribute to a more comprehensive and deeper understanding of gender differences in ICT self-efficacy. Although the sample size was relatively large, due to a large number of school subjects in Croatian elementary and secondary education, the dataset had a too small number of participants per subject for a more detailed analysis.

The research was conducted before the outbreak of the COVID-19 pandemic. Its consequences and, in particular, the closure of schools and the transition to online teaching and learning will emphasise the role of ICT use in education and the importance of gender differences in teachers' ICT self-efficacy as a subject of research. Recent research indicates that COVID-19 pandemic measures in education are particularly difficult for women and female teachers due to their overload with school obligations and household chores (EIGE, 2020; UNESCO, 2020). The extent to which the everyday life and teaching experience during COVID-19 pandemic affects teachers' ICT selfefficacy is a topic that has yet to be explored more intensively. 
This research also has some practical implications. Pointing to the relatively lower ICT self-efficacy of older female teachers, the findings suggest that strategies to enhance ICT self-efficacy of teachers should be particularly targeted at them. The relevant roles of previous shorter computer experience and more negative computer attitudes of older female teachers in their ICT self-efficacy indicate the need for their empowerment through high-quality trainings in computer skills as well as school management and collegial support within the school institution.

A similar level of self-efficacy for using ICT among the younger generations of teachers of both genders is an encouraging finding which could hopefully be followed by gender equality in other aspects of ICT use.

\section{Notes}

An early version of findings in this paper was presented at the conference ECER 2019, 2-6 September 2019, in Hamburg, Germany.

\section{Funding}

The authors disclosed the receipt of the following financial support for the research, authorship, and/or publication of this paper: This work was supported by the Croatian Academic and Research Network - CARNET.

\section{References}

Albion, P.R., Jamieson-Proctor, R., Finger, G. (2011). Age-related differences in ICT access and confidence among pre-service teachers. In: Williams, G., Statham, P., Brown, N., Cleland, B. (Eds.), Ascilite 2011. Changing Demands, Changing Directions: Proceedings. The University of Tasmania, Hobart, Australia, 21-32.

Bandura, A. (1994). Self-efficacy. In: Ramachandran, V.S. (Ed.), Encyclopaedia of human behaviour. Academic Press, New York, 71-81.

Bandura, A. (1997). Self-Efficacy: The Exercise of Control. Freeman, New York.

Cai, Z., Fan, X., Du, J. (2017). Gender and attitudes toward technology use: A meta-analysis. Computers \& Education, 105, 1-13.

Chaffin, A.J., Harlow, S.D. (2005). Cognitive learning applied to older adult learners and technology. Educational Gerontology, 31(4), 301-329.

Compeau, D.R., Higgins, C.A. (1995). Computer self-efficacy: Development of a measure and initial test. MIS Quarterly, 19(2), 1809-211.

Croatian Bureau of Statistics. (2020). Women and Men in Croatia. Croatian Bureau of Statistics, Zagreb.

Czaja, S.J., Charness, N., Fisk, A.D., Hertzog, C., Nair, S.N., Rogers, W.A., Sharit, J. (2006). Factors predicting the use of technology: Findings from the center for research and education on aging and technology enhancement (CREATE). Psychology and Aging, 21(2), 333-352.

EIGE (European Institute for Gender Equality). (2020). Gender Equality Index 2020. Digitalisation and the future of work. Publications Office of the European Union, Luxembourg.

Government of the Republic of Croatia, Expert Committee. (2014). New Colours of Knowledge: Strategy of Education, Science and Technology. Ministry of Science and Education, Zagreb. 
Gudek, B. (2019). Computer Self-Efficacy Perceptions of Music Teacher Candidates and Their Attitudes towards Digital Technology. European Journal of Educational Research, 8(3), 683-696.

Guo, R.X., Dobson, T., Petrina, S. (2008). Digital natives, digital immigrants: An analysis of age and ICT competency in teacher education. Journal of Educational Computing Research, 38(3), 235-254.

Hatlevik, I.K., Hatlevik, O.E. (2018). Examining the Relationship Between Teachers' ICT Self-Efficacy for Educational Purposes, Collegial Collaboration, Lack of Facilitation and the Use of ICT in Teaching Practice. Frontiers in Psychology, 9, 935.

Hong, K.S., Chai, M.L., Tan, K.W., Hasbee, U., Ting, L.N. (2014). ESL Teachers' Computer Self-Efficacy, Attitudes Toward Computer and Classroom Computer Use. Pertanika Journal of Social Sciences and Humanities, 22(2), 369-385.

Hoy, A.W., Spero, R.B. (2005). Changes in teacher efficacy during the early years of teaching: A comparison of four measures. Teaching and Teacher Education, 21(4), 343-356.

Joo, Y.J., Park, S., Lim, E. (2018). Factors influencing preservice teachers' intention to use technology: TPACK, teacher self-efficacy, and technology acceptance model. Journal of Educational Technology \& Society, 21(3), 48-59.

Klassen, R.M., Chiu, M.M. (2010). Effects on Teachers' Self-Efficacy and Job Satisfaction: Teacher Gender, Years of Experience, and Job Stress. Journal of Educational Psychology, 102(3), 741-756.

Krause, M., Pietzner, V., Dori, Y.J., Eilks, I. (2017). Differences and developments in attitudes and selfefficacy of prospective chemistry teachers concerning the use of ICT in education. EURASIA Journal of Mathematics, Science and Technology Education, 13(8), 4405-4417.

LimeSurvey GmbH. (2018). LimeSurvey: An Open Source survey tool. LimeSurvey GmbH, Hamburg.

Markočić Dekanić, A., Markuš Sandrić, M., Gregurović, M. (2019). TALIS 2018: Učitelji, nastavnici $i$ ravnatelji-cjeloživotni učenici. Međunarodno istraživanje učenja i poučavanja. NCVVO, Zagreb.

Ministry of Education of Singapore. (2020). Education Statistics Digest 2020. Ministry of Education, Singapore.

OECD.Stat. (2018). Distribution of teachers by age and gender. https://stats.oecd.org/Index . aspx?DataSetCode=EAG_PERS_SHARE_AGE\#

Papanastasiou, E.C., Angeli, C. (2008). Evaluating the Use of ICT in Education: Psychometric Properties of the Survey of Factors Affecting Teachers Teaching with Technology (SFA-T3). Educational Technology \& Society, 11(1), 69-86.

Perera, H.N., Calkins, C., Part, R. (2019). Teacher self-efficacy profiles: Determinants, outcomes, and generalizability across teaching level. Contemporary Educational Psychology, 58, 186-203.

Poulou, M.S., Reddy, L.A., Dudek, C.M. (2019). Relation of teacher self-efficacy and classroom practices: A preliminary investigation. School Psychology International, 40(1), 25-48.

Prensky, M. (2001). Digital Natives, Digital Immigrants Part 1. On the Horizon, 9(5), 1-6.

Rogošić, S. (2015). Construct Validity of the Questionnaire Measuring Technical and Socio-psychological Factors which Affect Successful Integration of ICT into Education. Croatian Journal of Education, 17(4), 983-1007.

Salajan, F.D., Schönwetter, D.J., Cleghorn, B.M. (2010). Student and Faculty Inter- Generational Digital Divide: Fact or Fiction? Computers \& Education, 55(3), 1393- 1403.

Sarfo, F.K., Amankwah, F., Konin, D. (2017). Computer Self-Efficacy among Senior High School Teachers in Ghana and the Functionality of Demographic Variables on Their Computer Self-Efficacy. TOJET: The Turkish Online Journal of Educational Technology, 16(1), 19-31.

Scherer, R., Siddiq, F. (2015). Revisiting teachers' computer self-efficacy: A differentiated view on gender differences. Computers in Human Behavior, 53, 48-57.

Siddiq, F., Scherer, R. (2016). The relation between teachers' emphasis on the development of students' digital information and communication skills and computer self-efficacy: the moderating roles of age and gender. Large-scale Assessments in Education, 4(1), 17.

Tarhini, A., Hone, K., Liu, X. (2014). Measuring the Moderating Effect of Gender and Age on E-Learning Acceptance in England: A Structural Equation Modeling Approach for an Extended Technology Acceptance Model. Journal of Educational Computing Research, 51(2), 163-184.

Turner, P., Turner, S., Van de Walle, G. (2007). How older people account for their experiences with interactive technology. Behaviour \& Information Technology, 26(4), 287-296.

UNESCO. (2020). Global Education Monitoring Report. Inclusion and Education: All means All. UNESCO, Paris.

Whitley, B.E. Jr. (1997). Gender differences in computer-related attitudes and behavior: A meta-analysis. Computers in Human Behavior, 13(1), 1-22.

Wolters, C.A., Daugherty, S.G. (2007). Goal structures and teachers' sense of efficacy: Their relation and association to teaching experience and academic level. Journal of Educational Psychology, 99(1), 181-193. 
J. Šabić received a PhD in Psychology (2018) at the University of Zagreb. Since 2016, he has been employed as junior researcher at the Centre for Educational Research and Development of the Institute for Social Research in Zagreb. His fields of interest are psychology of education and psychometrics.

B. Baranović is an emeritus scientist at the Institute for Social Research in Zagreb. Her main fields of interest are social inequalities in education, gender and education and national curriculum development. She published several books and numerous articles in scientific national and international journals.

S. Rogošić is an assistant professor at the Faculty of Teacher Education, University of Zagreb. Her areas of scientific interest are social and gender inequalities and the role of education in promoting social justice. At the Faculty of Teacher Education in Zagreb she teaches courses including Sociology of Education and Critique of Knowledge Structures. She published numerous articles in scientific national and international journals, and she is a member of national and international scientific organizations. 
